\title{
Dihaila Jheel-a new candidate for the Ramsar Convention
}

\author{
Asad R. Rahmani
}

\begin{abstract}
Wetland and waterfowl protection has become a major concern of the Indian Government recently. Among the $\mathbf{3 0 0}$ or so wildlife sanctuaries and national parks in India, wetland habitat is under-represented. There are nearly 20 bird sanctuaries, but only two wetlands-Bharatpur and Chilka-are listed under the Convention on Wetlands of International Importance especially as Waterfowl Habitat (Ramsar Convention). There is certainly great scope to add more sites to the Ramsar list of wetlands. The author has identified one candidate-Dihaila Jheel in Madhya Pradesh state-and exciting new initiatives are now being taken to protect and manage it with a view to recommending it as a Ramsar site.
\end{abstract}

During studies on the highly endangered great Indian bustard Ardeotis nigriceps a waterbody within the newly established Karera Bustard Sanctuary was recognized as extremely important for many birds (Rahmani, 1987). Known as Dihaila Jheel (jheel is Hindi for marsh), this 371ha waterbody is situated in the main bustard area of the sanctuary (Figure 1). There are five other waterbodies in the sanctuary, which has a total area of $202 \mathrm{sq} \mathrm{km}$. All are more or less man-made, with barrages to impound rainwater for irrigation.

Being entirely rain-fed, the size of Dihaila Jheel varies from year to year, depending on the quantity of the monsoon rains, which fall between July and September. The catchment area is more than $5 \mathrm{sq} \mathrm{km}$. Two barrages help to impound the water, which is released through sluice gates for irrigation. There is tremendous wastage of water as the sluice gates are frequently left open unnecessarily. Moreover, water leaks out through numerous holes in the bunds. As the water level falls, the exposed land is used for grazing, and in a drought year extensive crops are grown. Overall, Dihaila Jheel helps local human inhabitants in three ways: by providing water for irrigation during years of good rainfall, land for cultivation during poor rainfall years, Protection for Dihaila Jheel and pasture for livestock as the jheel dries out.

The jheel is also a haven for birds. With the onset of the monsoon in late June or early July, hundreds of lesser whistling teal*, comb duck, spotbilled duck, cotton teal, pheasant-tailed jacana, bronze-winged jacana, little grebe, egrets, and storks invade the newly inundated areas. The teal, comb duck and spotbilled duck soon leave the jheel to nest elsewhere. By September-October, migratory Palaearctic birds start arriving. Among ducks the first arrival is the pintail-one of the most common ducks in India. Within a few days, garganey, shoveler, wigeon, gadwall, common teal, redcrested pochard, common pochard, white-eyed pochard and tufted duck cover the jheel. By mid-November barheaded and greylag geese arrive. I counted up to 1500 geese in 1986 .

Among the storks, whitenecked, openbill, painted and blacknecked are seen commonly at Dihaila. In 1986-1987 I counted no fewer than 400 painted storks. The migratory white stork also visits infrequently, and in January 1987 ten were seen. The greater flamingo has become a regular feature at the jheel and since 1982 we have seen them every year.

*Scientific names are given in Table 1. 
Six species of raptor, the greater spotted eagle, tawny eagle, osprey, peregrine falcon, Pallas's fishing eagle and marsh harrier, have been recorded at the jheel. Cranes are represented by the resident sarus, and migrant demoiselle and common cranes. Twenty-seven species of waders have been identified during the last five years (Rahmani, 1987). As the water of the jheel recedes, a graduated feeding habitat is available for waders, dry, muddy, and submerged areas occurring in close proximity. The jheel and the surrounding fields have a special attraction for ruff; as the paddy is harvested in November, flocks are seen in the fields, picking at the fallen grains.

When migratory ducks start arriving in October

Table 1 Scientific names of the birds mentioned in the text

Little grebe Podiceps ruficollis

Little cormorant Phalacrocorax niger

Darter Anhinga rufa

Painted stork Mycteria leucocephala

Openbill stork Anastomus oscitans

Whitenecked stork Ciconia episcopus

White stork Ciconia ciconia

Blacknecked stork Ephippiorhynchos asiaticus

Flamingo Phoenicopterus roseus

Greylag goose Anser anser

Barheaded goose Anser indicus

Lesser whistling teal Dendrocygna javanica

Pintail Anas acuta

Common teal Anas crecca

Spotbilled duck Anas poecilorhyncha

Gadwall Anas strepera

Wigeon Anas penelope

Garganey Anas querquedula

Shoveler Anas clypeata

Redcrested pochard Netta rufina

Common pochard Aythya ferina

White-eyed pochard Aythya nyroca

Tufted duck Aythya fuligula

Cotton teal Nettapus coromandelianus

Comb duck Sarkidiomis melanotos

Tawny eagle Aquila rapax

Greater spotted eagle Aquila clanga

Marsh harrier Circus aeruginosus

Osprey Pandion haliaetus

Peregrine falcon Falcon peregrinus peregrinator

Pallas's fishing eagle Haliaeetus leucoryphus

Common crane Grus grus

Sarus crane Grus antigone

Demoiselle crane Anthropoides virgo

Pheasant-tailed jacana Hydrophasianus chirurgus

Bronze-winged jacana Metopidius indicus

Ruff Philomachus pugnax

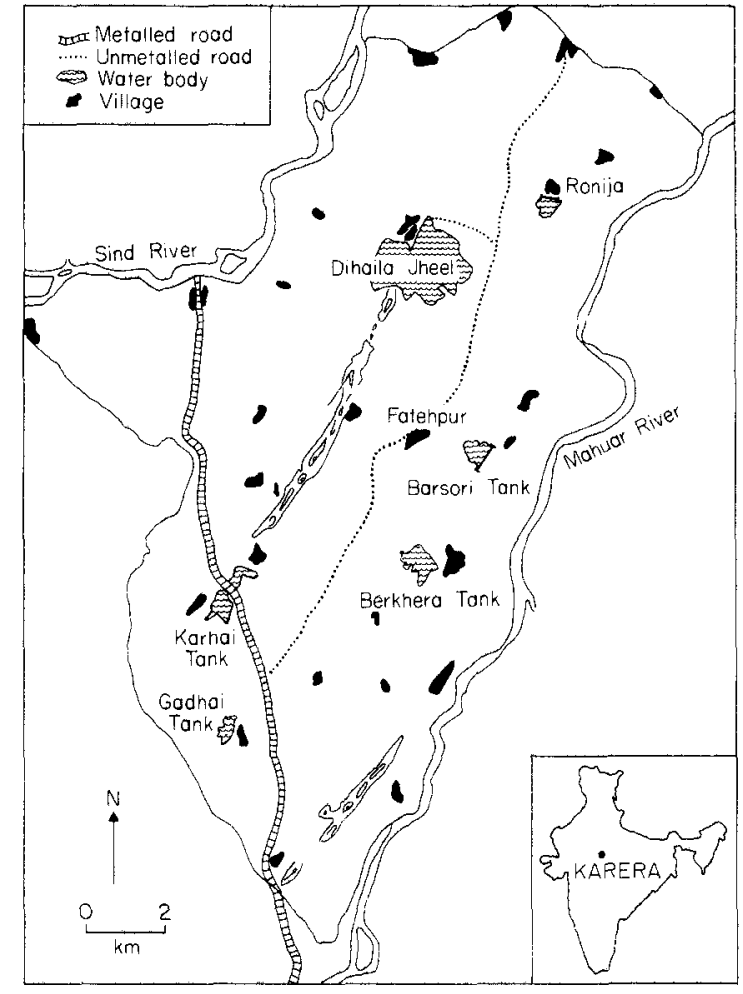

Figure 1. Karera Bustard Sanctuary (202.21 sq km).

the paddy is just ripening and farmers have difficulty in protecting their crops from depredation. One night's neglect and the crop is likely to be 'harvested' by the ducks. Similarly, the barheaded geese do tremendous damage to crops of bengal gram, which is grown extensively in the area. Bengal gram is also relished by the bustard. While the timid and rare bustard is tolerated by farmers, the barheaded geese are resented be. cause a raid by $300-400$ geese on a field can totally ruin the crop. In order to suppress the growing resentment against the birds it has been recommended that the Forest Department should grow bengal gram to decoy the geese from commercial crops, and that compensation should be paid to farmers for any damage by geese.

At present very few birds nest in Dihaila Jheel or in other waterbodies of the sanctuary. If groups of trees were to be planted near the jheel it is likely that colonial species such as egrets, ibises, cormorants and storks would colonize them for 


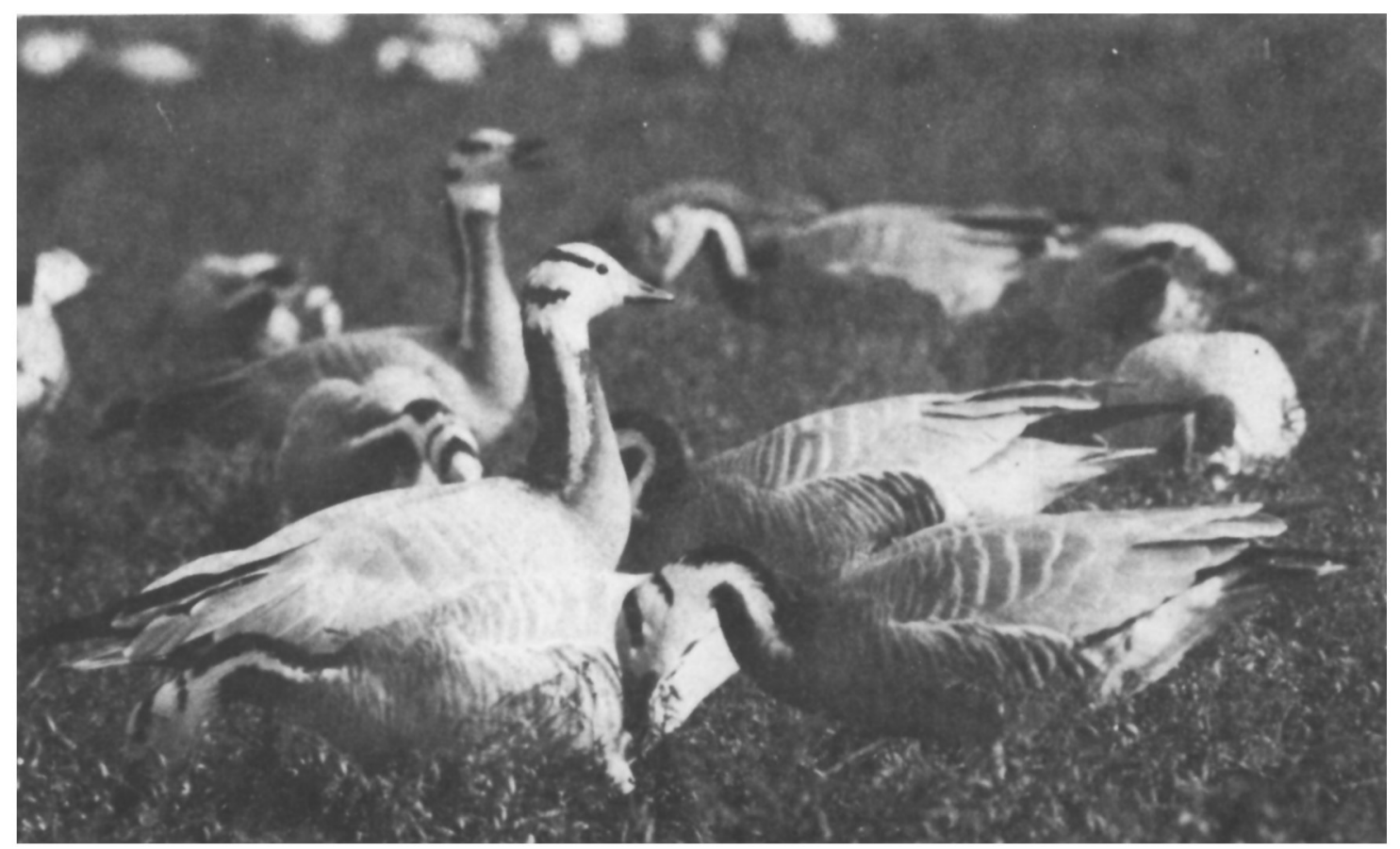

Bar-headed geese grazing in a field of bengal gram (Asad R. Rahmani).

breeding. Apart from the lack of trees there seems little to prevent these birds nesting. At Barsori Tank (Figure 1) there is already a small breeding colony of openbill storks in four acacia trees. In 1986 nearly 50 chicks were raised in this colony and a few nests of darter and little cormorant were recorded.

In 1985-1986 the Bombay Natural History Society started bird-ringing in Dihaila and within four months 4330 birds of 97 species, including land birds, were marked. A comparison of species diversity data from ringing records at Harike (Punjab), Bharatpur (Rajasthan), Chilka (Orissa) and Dihaila shows that Dihaila ranks second in species diversity, the first being Bharatpur. Of the four sites Dihaila scored the highest equitability index: i.e. species are more evenly distributed in Dihaila than in any of the other three areas studied (Vijayan, 1986).

\section{Conservation and management}

Before the Karera Bustard Sanctuary was established in 1981, Dihaila Jheel was a favourite place for wildfowlers. Once the sanctuary was Protection for Dihaila Jheel declared, however, adequate protection was given to all wildlife in the area. During the last few years very few incidents of poaching have been recorded and as a result more and more waterfowl are visiting this marsh.

Nevertheless, its future appears a little uncertain because of a plan to build a canal nearby. This will bring water from more than $50 \mathrm{~km}$ away and forms part of the main irrigation plan of the Mohini Sagar Project. Owing to lack of funds construction work is going slowly, but once the project is completed, in 5-10 years, the canal will greatly increase the irrigation facilities inside the sanctuary. After the canal is completed the water of Dihaila Jheel may no longer be required for irrigation and if that is the case there is the danger that the jheel itself will be drained and cultivated. On the other hand, the canal could become an asset by bringing water to the jheel. In that case the area of the jheel could be increased and water could be retained for a much longer period by refilling it from the canal. The Madhya Pradesh Forest Department is working in close collaboration with the Irrigation Department to protect the Dihaila Jheel from any adverse 
effects. Earlier the Irrigation Department agreed to change the route of two distributories to avoid the best nesting areas of the great Indian bustard. We expect the same concern from the department to protect Dihaila Jheel, especially since it lies within the sanctuary.

Dihaila Jheel and other waterbodies in the sanctuary fulfil many criteria for inclusion in the Ramsar Convention's list of wetlands of international importance. Dihaila Jheel is large (371 ha), and the total area of all the waterbodies in the sanctuary is nearly 560 ha. Although the waterbodies are partly man-made in that their waterstoring capacity is increased by bunds, they represent a particularly good example of wetlands characteristic of northern India. One of the criteria for Ramsar listing is that the wetland should 'regularly support 20,000 waterfowl'. We estimate that no fewer than 100,000 waterfowl are present during the winter in Dihaila Jheel and other waterbodies in the sanctuary.
A detailed plan for the protection and development of Dihaila Jheel was submitted to the Central and State Governments (see Rahmani, 1987). The main recommendations of the plan were:

(1) acquisition of Dihaila Jheel by the Madhya Pradesh Forest Department for proper management;

(2) judicious use of water to prevent wastage;

(3) control of unrestricted grazing for some months to allow the growth of grass;

(4) planting of trees in selected areas to provide nesting sites;

(5) development of basic tourist facilities;

(6) involving local people in the protection and management of Dihaila Jheel and surrounding areas;

(7) after developing it properly, the Indian Government should recommend Dihaila Jheel and the other waterbodies of the sanctuary for inclusion in the Ramsar Convention's list.

The Central Indian Government has agreed to all

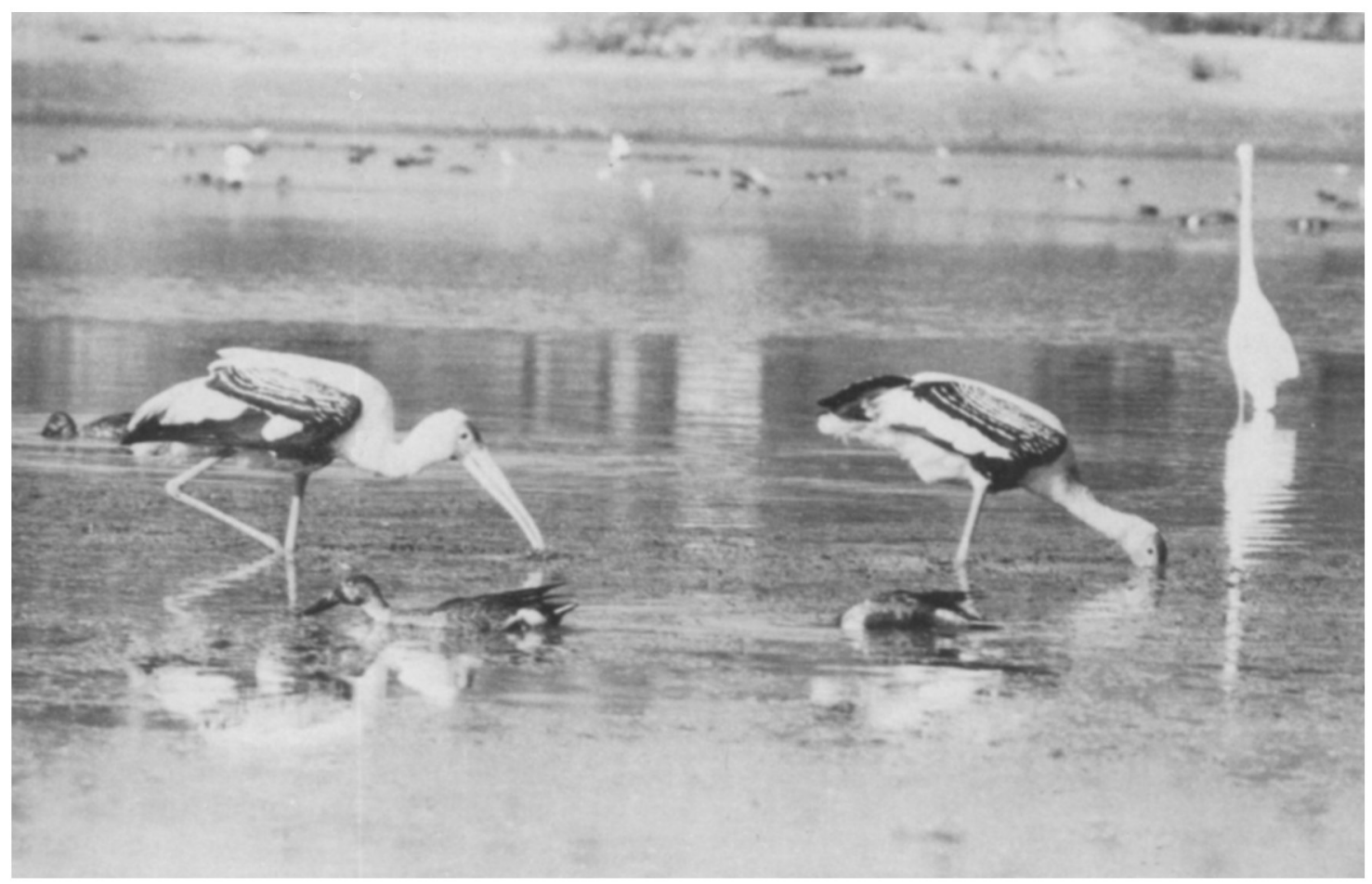




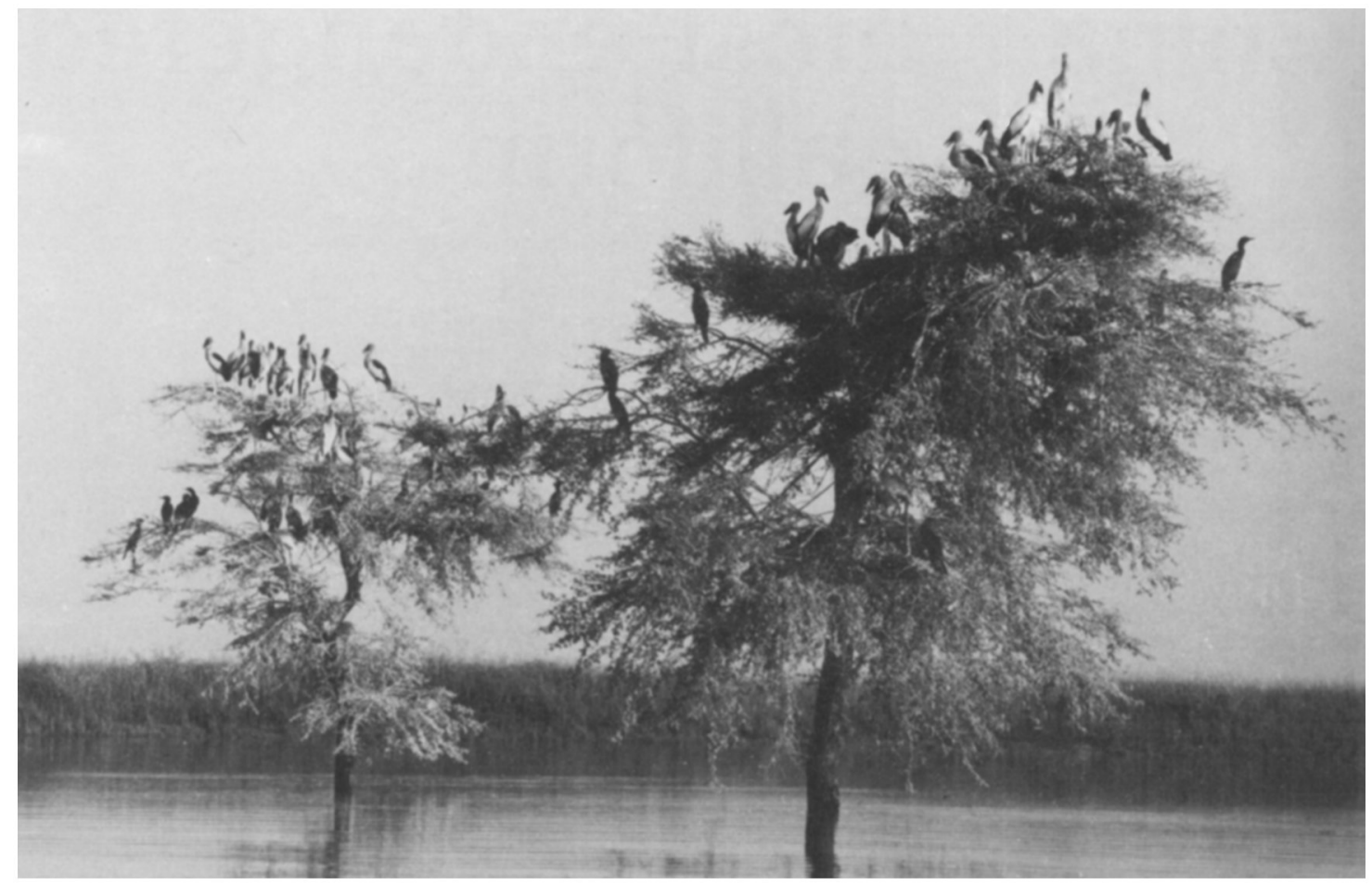

The colony of open-billed storks at Barsori Tank in Karera Bustard Sanctuary (Asad R. Rahmani).

the recommendations (M. K. Ranjitsinh, in litt., 1987) and the Madhya Pradesh State Government has been told to execute the project. It is fortunate that the Madhya Pradesh State Government is also keen to develop waterfowl sanctuaries, since wetlands are grossly underrepresented among the 40 or so sanctuaries in the state. It is hoped that in a few years time India will add another spectacular bird sanctuary to its already long list of protected areas.

\section{Acknowledgments}

This paper is dedicated to the late Dr Salim Ali, who guided, encouraged and supported us during all our studies. This study was undertaken as a part-time interest during my main work on the great Indian bustard under the Endangered Species Project. That project is funded by the US Fish and
Wildlife Service. Special thanks are due to Mr David Ferguson of the US Fish and Wildlife Service. I am also grateful to $\mathrm{Mr}$ Jagdish Chandra, Superintendent, Karera Bustard Sanctuary, for his help during the study period. Important help was also provided from the Bombay Natural History Society: Messrs J. C. Daniel, S. A. Hussain, V. S. Vijayan, Robert Grubh, Bharat Bhushan, Carl D'Silva and Ravi Sankaran.

\section{References}

Rahmani. A.R. 1987. Dihaila Jheel: Conservation Strategies. Bombay Natural History Society, Technical Report No. 12.

Vijayan, V.S. 1986. On conserving the bird fauna of Indian wetlands. Proc. Indian Acad. Sci. (Anim. Sci./Plant Sci.) Suppl, 91-101.

Asad R. Rahmani, Bombay Natural History Society, Hombill House (Museum Compound), Shaheed Bhagat Singh Road, Bombay 400023 , India. 